\title{
A Study on College EFL Teachers' Beliefs and Practices
}

\author{
Yao Xi ${ }^{1, a}$ \\ 1Dalian Neusoft University of Information, Software Park Road 8, Shahekou District, Dalian, \\ Liaoning Province, China. \\ axiyao@neusoft.edu.cn
}

Key words: teachers' beliefs, teaching practices, college English instruction.

\begin{abstract}
This study attempts to explore the non-English major college EFL teachers' beliefs and practices at three universities by quantitative and qualitative approaches. Through one and a half months' data collection, this study found that all of the participants were able to articulate their own teaching beliefs though, their teaching practices were not a hundred percent consistent with their professed beliefs due to some contextual factors. Thus, this study hopes to arouse colleges' attention on teachers' beliefs and to help college teachers realize the significance of teachers' beliefs to their teaching and professional development.
\end{abstract}

\section{Introduction}

Entering the $21^{\text {st }}$ century, college English education in China has witnessed a profound curriculum reform and innovation. Such a shift challenged teachers' beliefs about EFL teaching and learning, which triggered constant clashes between teachers' beliefs and practices (Zheng, 2015). Therefore, it is of great necessity to conduct an in-depth study on how teachers' beliefs relate to their teaching practices in a complex and dynamic teaching context.

\section{Literature review}

\subsection{Teachers' beliefs}

The research of teachers' beliefs originated in the mid-1970s, after which teachers' mental lives were spawned and took root. Synthesizing various meanings of teachers' beliefs, Pajares (1992) took the position that teachers' beliefs, teacher perspectives, and teaching ideology are perfectly consistent with each other. These views of belief constructs as inferences of what individuals say, intend, and do are just new jargons with old meanings. These orientations to teaching include beliefs teachers have about students and the learning process, about the role of schools in society, about teachers themselves, the curriculum, and pedagogy, about the purpose of schooling, about teacher responsibility for achieving goals, about beliefs that students are capable of achieving these goals, and about the ways in which teachers give meaning to these beliefs by their behavior in the classroom.

Despite Pajares' detailed description, this study preferably adopts the definition proposed by Borg (2001:186-187) "A belief is a proposition which may be consciously or unconsciously held, is evaluative in that it is accepted as true by the individual, and is therefore imbued with emotive commitment; further, it serves as a guide to thought and behavior." This definition may not satisfy all researchers' concern, but it covers main variables in ELT, which exerts a great influence on this study.

\subsection{Teachers' practice}

According to Calderhead (1984), teachers' practice is frequently described in terms of two major and apparently separate tasks. One is the task of instruction involving the selection and sequencing of appropriate lessen content, the transmission of knowledge, skills and attitudes, and the provision of feedback to students about their learning process. The other is the task of classroom management, involving the organization of students and materials, the establishment of classroom procedures to facilitate learning and dealing with disruptions and threats to classroom order. Therefore, teachers' practice does not simply equal to teachers' behavior, yet it contains two areas of teacher activity which are often closely intervened. Experienced teachers may be good at dealing with these two tasks 
simultaneously, while inexperienced teachers may be weak in that. This part of teaching task, thus, poses great demands on teachers' beliefs.

\section{Research methodology}

\subsection{Research questions}

In order to extrapolate how the non-English major college EFL teachers' beliefs relate to their teaching practices, the following questions will be used to guide this study.

1. What general beliefs do non-English major college EFL teachers hold in terms of language, teaching, learning, learners, self as a teacher, and curriculum?

2. How do the six key teachers' beliefs influence their lesson plans?

3. What relevance that exists in relating the teachers' beliefs to their teaching practices?

4. What factors influence the relationship between teachers' beliefs and their teaching practices?

\subsection{Participants}

The participants of this study are composed of two parts of teachers, including the respondents to the questionnaire and six teachers involved in the case study.

A total number of 60 teachers who filled out the questionnaire were respectively selected from three key universities with 20 from a normal university, with 20 from a comprehensive university, and with 20 from a polytechnic university. Among them, $83.3 \%$ are female and $16.7 \%$ are male. $18.3 \%$ of the teachers have a teaching experience under 5 years, $41.7 \% 5$ to 10 years, $15 \% 11$ to 15 years, $13.3 \% 16$ to 20 years, $6.7 \% 21$ to 25 years, and $5 \%$ above 25 years.

Six teachers were randomly selected from the respondents to the questionnaire as the key participants of the case study, among which three of them were from the normal university, two of them were from the comprehensive university, and one of them was from the polytechnic university.

\subsection{Instruments}

In this study, both quantitative approach and qualitative approach are adopted to collect data. A questionnaire is employed to investigate the general characteristics of the non-English major college EFL teachers' belief systems, whereas a qualitative, multiple-case study is employed to gain an indepth understanding of the relationship between the teachers' professed beliefs and their classroom practices. Moreover, how the implicit belief systems are embodied in the teaching plans and carried out as the form of explicit classroom practices is also involved.

\subsection{Data collection}

Data collection started with a questionnaire about teachers' beliefs. But before distributing the formal questionnaire to participants, a pilot-study was conducted in order to collect feedbacks about how the instrument worked and whether it performed the job it had been designed for. After carefully revising, the final version of the questionnaire with forty items was formed and distributed to participants with the help of three teachers from the target universities respectively.

The case study consisted of the in-depth, semi-structured interviews with the six key teachers, 36 hours classroom observations, audio recordings of teaching practices, and researcher's field notes and reflective journals.

\subsection{Data analysis}

Statistics on questionnaires were analyzed by SPSS 25.0 immediately they were taken back. Item analysis was firstly conducted to measure the internal consistency reliability of it by the Cronbach Alpha coefficient of which the total scale was .913 which was pretty high. This means that all the items making up the various multi-item scales within the questionnaire achieved homogeneity. Thus, this questionnaire is feasible to measure teachers' beliefs. Then all the responses were analyzed by descriptive statistics (mean scores and standard deviations). Furthermore, the descriptive results were analyzed separately to show teachers' beliefs regarding language, language learning, language teaching, learners, self as a teacher, and college English curriculum. 
Three steps were conducted to analyze the data of interviews and class observations. Initially, all the interviews were manually transcribed to identify words, phrases, or word-phrase clusters for the purpose of further analysis. Secondly, whenever an interview or lesson observation finished, the data transcripts were read carefully for several times and were coded according to emerging themes. Thirdly, after finishing all the classroom observations and interviews, all the data were read and checked again. To validate the findings, researcher triangulation was used to make sure the reliability of the final results.

\section{Findings and discussion}

The four major findings came from different data can be summarized as follows:

First of all, most of teachers responding to the questionnaire had positive beliefs which highly kept up with the new developments of college English instruction in China. With respect to the six branches of teachers' beliefs on college English instruction, teachers generally hold an advanced and innovative orientation. A majority of teachers regarded language as meaningful communication, which can be learned in non-academic and social situation. In other words, teachers took a functionbased view toward language, which focuses on the use of authentic language within situational contexts and seeks to provide opportunities for functional and communicative language use in the classroom (Johnson 1992). However, teachers didn't show preference to the function-based view of language teaching. They mainly held a rule-based orientation which emphasizes the importance of grammatical rules and a conscious understanding of the language system. With reference to language learning, teachers mostly stressed the importance of foreign culture to language learning. In a way, this view of language learning has a close connection with teachers' beliefs on language. Learners, in the eyes of many teachers, were teachers' partners involved in decisions about what activities to carry out, what topics to discuss and what books to read. At the same time, teachers viewed themselves as motivators, organizers, and facilitators working largely from a social constructivist perspective. Teachers' beliefs on college English curriculum mainly focused on the humanistic curriculum orientation which attached importance to the development of students' self-confidence and learning interests. This also reflected college English teachers' core beliefs that college English instruction should fully motivate students' learning interests and cultivate their self-confidence in order to achieve the best teaching effects.

Secondly, the six teachers in the multi-case study can clearly articulate their own beliefs in terms of language, language learning, language teaching, learners, self as a teacher and college English curriculum. Besides, most of teachers pointed out that their own experience as English learners would exert great influence on the development of teachers' beliefs. For example, Teacher A reported, "my teachers' strict attitude of teaching and meticulous consideration to students impress me so much that I always model myself on my teacher and follow my teacher's teaching methods." Teacher E also said, "When answering questions, she would correct me in tense, voice, and grammar as soon as I made these mistakes. I benefited a lot from that the teacher corrected me immediately, because I could be clear about my mistakes and remember the grammatical rules easily, so I would not make such errors in the following process of teaching." Their cases were agreed with the report of Richards \& Lockhart (2000) that teachers' beliefs about teaching were often a reflection of how they themselves were taught by their teachers. Through investigating their lesson plans, this study also found that each of teachers may design the teaching activities and make some predetermined decisions based on their beliefs. Although teachers' decisions made in planning the lessons differed dramatically from that of the other's, teachers' own lesson plans were internally consistent with their own deeper underlying beliefs about college English instruction.

Thirdly, the six teachers' teaching practices were approximately in consistent with their professed beliefs. Moreover, a single belief held by teachers would be put into practice through several distinct teaching activities, and vice versa. A single practice would be supported by more than one belief. However, it is impossible to match teaching practices a hundred percent with teachers' beliefs. There were more or less some departures from teachers' beliefs.

Finally, teachers' reflective comments on their teaching practices revealed that there were certain 
contextual factors interfering with the implementation of teachers' beliefs to practices. Those contextual factors perceived by the teachers were both physical and ideological in nature, including class time, class size, students' ability, teaching objectivity, teachers' ability, and students' personalities. Among them, class time and class size were two key influential factors to college English instruction.

\section{Conclusion}

This study presented a panorama of the non-English major college EFL teachers' beliefs, which may provide some inspiring implications for EFL teaching and teacher education in tertiary level.

Firstly, teachers' beliefs are culture-oriented in nature, which is infeasible to confuse the EFL teachers' belief systems with the ESL teachers' belief systems.

Secondly, college EFL teachers should be encouraged to be reflective practitioners, who need to reflect on their teachings frequently.

Thirdly, great attention to the physical and ideological contexts of college English teaching is required in the college English curriculum reform.

\section{References}

[1] Zheng, H. Y., Teacher beliefs as a complex system: English language teachers in China, London: Springer, 2015.

[2] Pajares, M. F., Teachers' Beliefs and Educational Research: Cleaning up a Messy Construct, Review of Educational Research, vol.62, pp.307-332, 1992.

[3] Borg, M., Teachers' beliefs, ELT Journal, vol.55(2), pp.186-188, 2001.

[4] Calderhead, J., Teachers' Classroom Decision-Making, East Sussex, Eastbourne: Holt Rinehart and Winston Ltd., 1984.

[5] Johnson, K. E., The Relationship between Teachers' Beliefs and Practices during Literacy Instruction for Nonnative Speakers of English, Journal of Reading Behavior, vol.24, pp.83-108, 1992.

[6] Richards, J. C. \& C. Lockhart, Reflective Teaching in Second Language Classrooms, Beijing: Foreign Language Teaching and Research Press, 2000. 